\title{
From transitory erythema to pheocromocytoma
}

\author{
Ana Valea ${ }^{1,2}$, Mara Carsote ${ }^{3,4}$, Simona Elena Albu, \\ Mihai Cristian Dumitrascu, ${ }^{3,5}$, Florica Sandru ${ }^{3,6}$ \\ ${ }^{1}$ Clinical County Hospital, Cluj-Napoca, Romania \\ 2"Iuliu Hatieganu" University of Medicine and Pharmacy, Cluj-Napoca, Romania \\ 3"Carol Davila" University of Medicine and Pharmacy, Bucharest, Romania \\ 4"C.I. Parhon" National Institute of Endocrinology, Bucharest, Romania \\ ${ }^{5}$ Emergency University Hospital, Bucharest, Romania \\ ${ }^{6}$ Elias Emergency University Hospital, Bucharest, Romania
}

\begin{abstract}
This is a case report of a female with transitory erythema who was found with thrombocytosis caused by a pheocromocytoma. The skin changes were not accompanied by typical manifestations of an adrenergic crisis although she had high blood pressure episodes without skin colour changes. Both the erythema and the arterial hypertension controlled after the adrenal tumour was removed.

Pheocromocytoma associates not only the excessive production of metanephrines and normetanephrines but also other factors like interleukins (for instance, IL-6, causing a general inflammatory syndrome including reactive thrombocytosis) eritropoietin or parathormone related peptide. Thrombocytosis is extremely rare associated with cathecolamines producing tumour and it may become a supplementary contributor to cardiovascular risk.
\end{abstract}

Keywords: erythema, abdominal tumour, pheocromocytoma

\begin{abstract}
Abbreviations
FUO $=$ fever of unknown origin

$\mathrm{PTH}=$ parathormone

$\mathrm{PTHrP}=$ parathormone related peptide
\end{abstract}

\section{INTRODUCTION}

Pheocromocytoma associates not only the excessive production of metanephrines and normetanephrines but also (less frequent) other factors like interleukins (for instance, IL-6 causing a general inflammatory syndrome including reactive thrombocytosis), eritropoietin or parathormone related peptide (PTHrP) $(1,2)$. This are rarely found and they are not associated with a specific genetic pattern, for instance with pheocromcytomas from type 2 multiple endocrine neoplasia (3).

\section{AIM}

We introduce an adult female subject with atypical presentation for a pheocromocytoma: erythema due to thrombocytosis.

\section{MATERIAL AND METHOD}

This is a case report. The clinical as well as biochemical and endocrine evaluation is introduced.

\section{CASE REPORT}

\section{Admission}

This is a 48 years old non-smoking female coming from endemic area. She has normal menses. Her medical personal and family background is irrelevant. She presented during the last 2 years a few episodes of erythema which was transitory and accompanied by transpirations. Apparently there was no trigger and the remission was spontaneous within minutes. The blood pressure and pulse was normal, except she experienced other episodes of 
high blood pressure (the highest value of 200 $\mathrm{mmHg}$ for systolic component) which were not accompanied by skin changes but by headache. These episodes were considered by the patient related to a period of emotional stress and she felt chronic asthenia.

Her general physician considered that, apart from dermatological evaluation which was unrevealing, an abdominal ultrasound might help as a routine procedure. The evaluation raised the question of a right adrenal tumour so the patient was referred for an endocrine check-up.

\section{Endocrine assessment}

During admission the patient did not repeat the episodes but the complete panel of evaluation for adrenal tumours was done. Adrenal androgens and glucocorticoid axes were within normal limits. A pheocromocytoma was confirmed based on urinary metanephrines of 1,436 $\mu \mathrm{g} / 24$-hour (normal: 50 $350 \mu \mathrm{g} / 24$-hour), respective plasmatic metanephrines of $602 \mathrm{pg} / \mathrm{ml}$ (normal: 10-90 pg/ml); urinary normetanephrines of 2,277 $\mu \mathrm{g} / 24$-hour (normal: $100-600 \mu \mathrm{g} / 24$-hour), respective plasmatic normetanephrines of 2,054 pg/ml (normal: 20$200 \mathrm{pg} / \mathrm{ml}$ ) with a chromogranin A twice as normal upper limit and normal serum calcium and PTH (parathormone). Left ventricular hypertrophy with mix repolarisation anomalies was found at electrocardiogram (Figure 1).

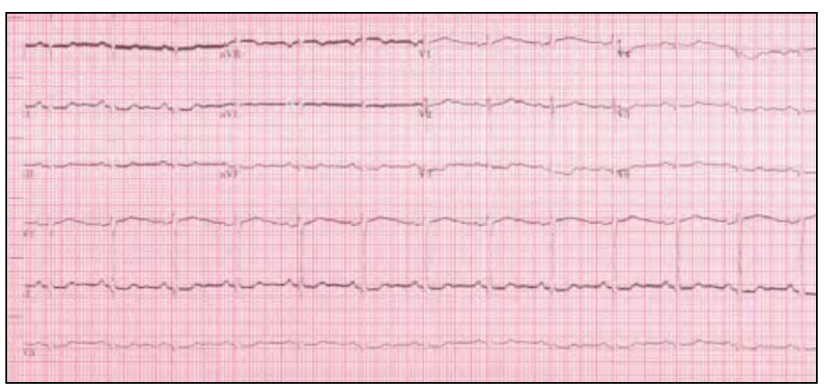

FIGURE 1. Left ventricular hypertrophy was found at electrocardiogram on a patient with normal blood pressure and a 2 years history of high blood pressure episodes

Thyroid assessment showed a several small thyroid nodules with normal thyroid function and negative antibodies against thyroid, and a normal level of calcitonin (Figure 2). Also the hemogram showed trombocytosis of $450,000 / \mathrm{mmc}$ (normal levels between 150 and $400,000 / \mathrm{mmc}$ ) and the value was the same for 3 assays without other anomalies of hemogram. The other markers of inflammation like erythrocytes sedimentation rate, reactive $\mathrm{C}$ protein, fibrinogen were within normal limits.

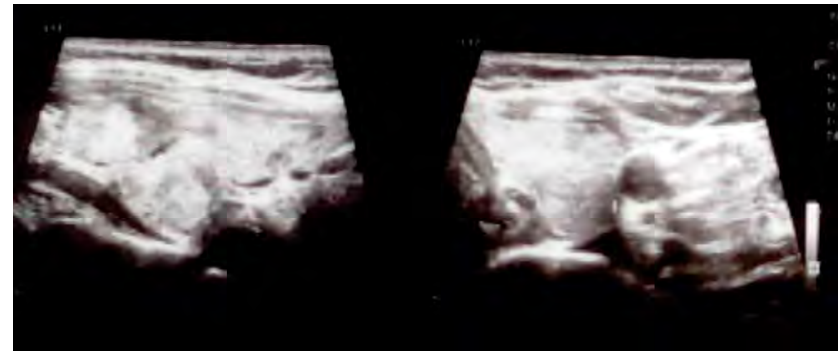

FIGURE 2. Multinodular goitre at thyroid ultrasound on an adult female with normal thyroid function and negative thyroid autoimmunity

Computed tomography identified an adrenal tumour of 4.9 by $3.8 \mathrm{~cm}$ suggestive for a pheocromocytoma (Figure 3).

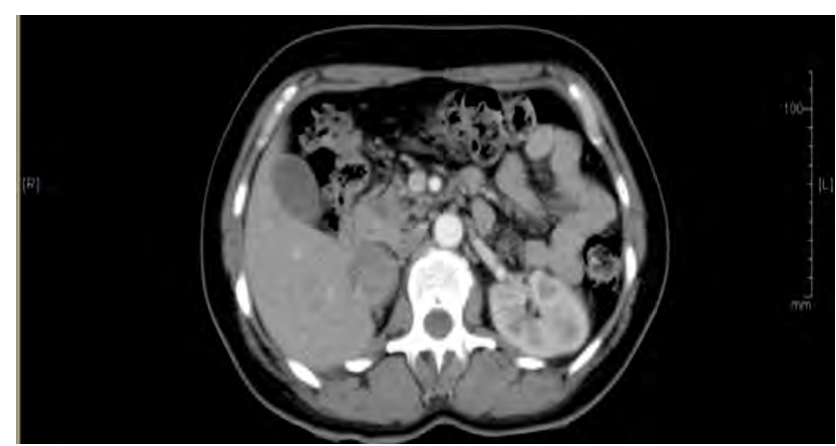

FIGURE 3. Computed tomography: right adrenal tumour of 4.9 by $3 . s 8 \mathrm{~cm}$

\section{Approach}

Unilateral laparoscopic adrenalectomy with adequate pre-operatory preparation was done and the clinical outcome was without events during follow-up. The hormonal profile and hemogram normalised after surgery as well as the blood pressure.

\section{DISCUSSION}

\section{Cardiovascular profile}

The presence of left ventricular hypertrophy represents a hallmark of chronic exposure to high blood pressure even undetected between the symptomatic episodes of high blood pressure. Endocrine screening of arterial hypertension among young adults is essential $(4,5)$. In this case the episodic features of the blood pressure increase were suggestive for a potential adrenaline/noradrenaline discharge. Generally arterial hypertension of any cause had a high prevalence in unselected persons up to $40 \%$ and the incidence is age-related $(4,5)$. $90-95 \%$ of cases are essential while $5-10 \%$ of them had secondary (probably reversible) causes as it is suggested by high blood pressure unresponsive to classical therapy, episodic increase of blood pres- 
sure values, and diagnosis at young age (at less than $40-50$ years) as seen in this case $(4,5)$.

\section{Thyroid check-up}

The association of pheocromocytoma with multinodular goitre is most probably incidental. If a young adult presents high blood pressure and transpirations a hyperthyroidism should be suspected $(6,7)$.

\section{The detection of an adrenal tumour on a hypertensive patient}

Endocrine causes of high blood pressure related to adrenal tumours involve adrenal Cushing's syndrome, Conn syndrome, adrenocortical carcinoma, pheocromocytoma and a tumour-like aspect (mainly bilateral) is also found in congenital adrenal hyperplasia $(8,9)$. Generally the tumour removal corrects the blood pressure unless long time prior exposure caused an increased stiffness of arterial wall and chronic blood pressure is expected $(10,11)$. In our case the blood pressure normalized after surgery. Also, there is a chance that arterial hypertension is essential and the adrenal mass is non-secretor. The incidence of adrenal incidentaloma is age-related but also high blood pressure has the same pattern of incidence $(12,13,14)$.

\section{Thrombocytosis and pheocromocytoma}

This association represents the most interesting part of the presented case. Generally, pheocromo-

\section{REFERENCES}

1. Carvalho Cunha N, Gomes L, Saraiva J, Paiva I. Interleukin-6 Producing Pheochromocytoma: A Rare Cause of Systemic Inflammatory Response Syndrome. Case Rep Endocrinol. 2019 Mar 24:2019:7906272.

2. Ciacciarelli M, Bellini D, Laghi A, Polidoro A, Pacelli A, Bottaccioli AG, Palmaccio G, Stefanelli F, Clemenzi P, Carini L, Iuliano L, Alessandri C. IL-6-Producing, Noncatecholamines Secreting Pheochromocytoma Presenting as Fever of Unknown Origin. Case Rep Med. 2016; 2016:3489046.

3. Valea A, Radu O, Morar A, Ghemigian A, Carsote M. Synchronous medullar thyroid cancer and primary hyperparathyroidism on a female within the sixth decade of life with positive family history for type $2 \mathrm{~A}$ MEN syndrome. Journal of Medical Practice. 2016;4(47)-11:346-349.

4. Trifanescu R, Carsote M, Caragheorgheopol A, Hortopan D, Dumitrascu A, Dobrescu M, Poiana C. Screening for secondary endocrine hypertension in young patients. Maedica (Buchar). 2013 Jun; 8(2):108-15.

5. Grasso M, Boscaro M, Scaroni C, Ceccato F. Secondary Arterial Hypertension: From Routine Clinical Practice to Evidence in Patients with Adrenal Tumor. High Blood Press Cardiovasc Prev. 2018 Dec; 25(4):345-354

6. Dumitru N, Ghemigian A, Carsote M, Albu SE, Terzea D, Valea A. Thyroid nodules after initial evaluation by primary health care cytoma may produce a cocktail of amines, cytokines, neuropeptides that act on skeleton, inflammatory or cardiovascular system $(15,1)$. Interleukins cause fever apparently of unknown cause (fever of unknown origin or FUO), weight loss, high reactive $\mathrm{C}$ protein, changes of hemogram like thrombocytosis, leucocytosis, anaemia $(16,17)$. Actually, IL-6 is either produced by the tumour itself (and immunohystochemistry on the adrenal tumour should confirm it) or it is stimulated by circulating norepinephrine as a reactive response $(18,19)$. Overall, pheocromocytoma, a rare tumour with an incidence of 1/100 000 person-year, associates the classical triad of headache, palpitations and sweating but large variations of clinical presentation is described including transitory erythema as seen in this case without fever (20). This atypical manifestations complicate the index of suspicion in a very severe condition if left untreated.

\section{CONCLUSION}

Practitioners should pay attention to even small skin changes that may underline severe apparently unrelated conditions. Thromobocytosis associated with a pheocromocytoma is a rare event.

practitioners: an ultrasound pictorial essay. Archives of the Balkan Medical Union. 2016:51(3):434-438.

7. Singh I, Hershman JM. Pathogenesis of Hyperthyroidism. Compr Physiol. 2016 Dec 6;7(1):67-79.

8. Poiana C, Chirita C, Carsote M, Hortopan D, loachim D, Corneci CM, Stanescu B. Adrenal and Pituitary Incidentalomas in a Case of Cushing's Syndrome. Chirurgia 2013;6(108):886-891.

9. Carsote M, Ghemigian A, Valea A, Dumitrascu A, Chirita C, Poiana C. Sublinical Cushing's syndrome with bilateral adrenal tumours in a patient with gallbladder multiple stone: Therapeutical options. Ars Medica Tomitana. 2015;3(21);124-127.

10. Pappachan JM, Tun NN, Arunagirinathan G, Sodi R, Hanna FWF. Pheochromocytomas and Hypertension. Curr Hypertens Rep. 2018 Jan 22;20(1):3. doi: 10.1007/s11906-018-0804-z.

11. Valea A, Ghervan C, Carsote M, Albu SE, Georgescu CE. Different surgical options in Cushing's disease. Journal of Surgical Sciences. 2016;3(1):39-43.

12. Gheorghiu M, Hortopan D, Dumitrascu A, Caragheorgheopol A, Stefanescu A, Trifanescu R, Niculescu D, Baciu I, Carsote M, Poiana C, Badiu C, Coculescu M. Age-related endocrine tumors: nonfunctioning adrenal tumors as compared to pituitary adenomas. Acta Endocrinologica, 2009;V(3):371-384. 
13. Gheorghisan-Galateanu AA, Carsote M, Valea A. Incidentaloma: from general practice to specific endocrine frame. J Pak Med Assoc. 2017.67(6):917-922.

14. Poiana C, Chirita C, Carsote M, Hortopan D, loachim D, Corneci CM, Stanescu B. Adrenal and Pituitary Incidentalomas in a Case of Cushing's Syndrome. Chirurgia 2013;6(108):886-891.

15. Carsote M, Radoi V, Geleriu A, Mihai A, Ferechide S, Opris D, Paun $D$, Poiana C. The serotonin and the bone assessment. Journal of Medicine and Life 2013;6(2):151-155.

16. Bazhenova L, Du EZ, Bhoyrul S, McCallum J, Saven A. Reactive thrombocytosis associated with a pheochromocytoma. Thromb Haemost. 2005 Aug;94(2):460-2.

17. Minetto M, Dovio A, Ventura M, Cappia S, Daffara F, Terzolo M, Angeli A. Interleukin- 6 producing pheochromocytoma presenting with acute inflammatory syndrome. J Endocrinol Invest. 2003 May;26(5):453-7.
18. Takagi M, Egawa T, Motomura T, Sakuma-Mochizuki J, Nishimoto $\mathrm{N}$ Kasayama S, Hayashi S, Koga M, Yoshizaki K, Yoshioka T, Okuyama A, Kishimoto T. Interleukin-6 secreting phaeochromocytoma associated with clinical markers of inflammation. Clin Endocrinol (Oxf). 1997 Apr;46(4):507-9.

19. Suzuki K, Miyashita A, Inoue Y, Iki S, Enomoto H, Takahashi Y, Takemura T. Interleukin-6-producing pheochromocytoma. Acta Haematol. 1991;85(4):217-9.

20. Siddiqui UM, Matta S, Wessolossky MA, Haas R. Fever of Unknown Origin: Could It Be a Pheochromocytoma? A Case Report and Review of the Literature. Case Rep Endocrinol. 2018 Jul 3;2018:3792691. 